\title{
International community in search of legal answers to the digitalisation challenges
}

\author{
Anatoly Yakovlevich Kapustin ${ }^{1 *}$, Sayana Bairovna Balkhaeva ${ }^{1}$, Andrey Evgenievich \\ Pomazansky², and Azamat Tynyshtykbaevich Aldabergenov ${ }^{3}$ \\ ${ }^{1}$ Institute of Legislation and Comparative Law under the Government of the Russian Federation, \\ Department of Foreign Constitutional, Administrative, Criminal Legislation and International Law, \\ Moscow, Russia \\ ${ }^{2}$ Institute of Legislation and Comparative Law under the Government of the Russian Federation, \\ Department of Constitutional Law, Moscow, Russia \\ ${ }^{3}$ Almaty Academy of the Ministry of Internal Affairs of the Republic of Kazakhstan named after \\ Makan Esbulatov, Training Center on Counteraction of Extremist Activity, Almaty, Kazakhstan
}

\begin{abstract}
The purpose of the study is to analyse the regulatory potential of international law taking into account its main focus for the regulation of new relations associated with digitalisation processes. The research methodology consisted of formal-legal, formal-logical, interpretation of law as well as general-scientific methods. The research resulted in the solution of problems involving the determination of the key areas of international cooperation in respect of those issues in which the need for international legal regulation has already most clearly manifested so far. The authors attributed to them the international cooperation under the auspices of international organisations, primarily the United Nations, monitoring compliance with international law and preventing its possible violations, solving global problems such as climate change, sustainable development, migration, terrorism and armed conflicts. The novelty of the research lies in the very formulation of the problem as well as the conclusion that international legal regulation in the field of digitalisation should be based on international consensus. At the same time, it is possible to reach such a consensus both within the framework of existing international organisations, which can be adapted to address new issues due to their universality, and through the development of new international agreements.
\end{abstract}

Keywords: digitalisation, international law, international cooperation, international organisations, sustainable development

\section{Introduction}

Digitalisation and new technologies implementation have become ingrained in our everyday lives and continue to influence many areas of the social life of society. In addition to unassailably positive consequences of the described phenomena resulting in the growth of labour productivity, strengthened economic ties and raised level and quality of human life,

\footnotetext{
* Corresponding author: anatoly.kapustin@gmail.com
} 
they are fraught with threats of the global order for the normal functioning of the international community.

International law has an undeniable regulatory potential for the development and construction of solutions that meet the interests of the entire international community. Taking into account the consensus nature of international law characterised by the absence of any single centralised law-making body and, consequently, the absence of any hierarchical regulatory or legal structure, it is most optimally capable of harmonising the interests of states in new technological areas of activity.

Advances in science and technology are driving rapid global change. The waves of technological change driven by inventions ranging from steam power to electricity and the automobile have influenced the economic development and social transformation throughout history. German professor Klaus Schwab, the founder and all-time president of the World Economic Forum in Davos, claims that now humanity is on the verge of the fourth industrial revolution, where "already at the outset of this revolution, its basic signs can be seen, i.e. a fusion of technologies that is blurring the lines between the physical, digital and biological spheres" [1].

Against this background, international law becomes a necessary regulator of interstate relations for the use of technological advances. However, there are specificities regarding the ability of international law to respond to those challenges. In particular, the scope and application of international law to new technologies is subject to structural constraints inherent in the consensus nature of international law [2]. Public international law can be characterised by the absence of any unified centralised law-making, law enforcement and control bodies, and consequently, absence of a hierarchical regulatory and legal structure. Also, public international law is a "fragmented" legal order, in which there is a high probability of contradictions and the resulting need to establish rules for resolving possible conflicts between provisions of law [3].

However, by cooperating on global issues, states acquire mutual advantages that are created through a consolidated coordination of interests. In this regard, it seems to be true that international law can provide the basis for the organisational mechanism for implementing the desire of states to cooperate [4].

\section{Methods}

The methodological basis for the research is the general, general-scientific and specificscientific methods of cognition used by legal science in the object-subject sphere of cognition of the general theory of law. In addition, used are some synthetic and/or integrative research methods which are included in the methodology of interdisciplinarity relevant for the modern socio-humanistic science.

\section{Outcomes and discussion}

Currently, international organisations represent a platform where the positions of states concerned are coordinated. Thus, in September 2018, the UN Secretary General unveiled the Strategy on New Technologies (hereinafter referred to as the Strategy), in accordance with which the UN faces the challenge to regulate not only the past and present development and deployment of technologies but also the uncertain future represented by those technologies [5].

The history of human development has shown that many technological advances have contributed to the development of international law. In this context, the example of 
international humanitarian law (IHL) is quite typical the content of which expanded as new technological discoveries were introduced into military activities [6].

Currently, there is an active discussion on the prohibition of the use of lethal autonomous weapons (hereinafter LAW). So, as of February 2021, only nineteen states are calling for such a ban. Those countries are presented in the table below.

Table 1. States which lobby for the prohibition of the use of lethal autonomous weapons.

\begin{tabular}{|c|c|c|c|}
\hline Algeria & Cuba & Vatican & Peru \\
\hline Argentina & Ecuador & Mexico & State of Palestine \\
\hline Bolivia & Egypt & Nicaragua & Venezuela \\
\hline Chile & Ghana & Pakistan & Zimbabwe \\
\hline Costa Rica & Guatemala & Panama & \\
\hline
\end{tabular}

Thus, states calling for a ban on LAWs are technically "backward" in contrast to states that do not want to lose their significant advantage in war over those that cannot use or afford that technology [7].

Within the UN, one of the main coordinating bodies involved in digitalisation developments is the Chief Executives Board for Coordination (hereinafter referred to as the $\mathrm{CEBC}$ ). CEBC's role is to provide general guidance, coordination and strategic orientation for the UN as a whole. It is also a forum for policy debate at the highest level within the UN.

The core subjects addressed in the CEBC Report adopted at the thirty-seventh session (April 8-9, 2019) are artificial intelligence (AI), education and professions of the future as well as sustainable urban development. The major focus was on unleashing the artificial intelligence potential for developing countries to keep balance between innovation with commercial interests and the well-being of individuals who deserve to be considered equal participants with rights, powers and a voice in technological development [8].

Currently, AI and robotics are emerging as most promising, complex and rapidly progressing developments among later technologies. The term "AI" refers to computer systems that demonstrate the ability to perform problem solving, predictive analysis and other cognitive tasks.

In recent years, improved machine learning algorithms capable of self-learning from large datasets have raised legitimate concerns but also open up new opportunities for improving decision-making, informing policy choices and achieving shared goals. AI is being improved by related developments including the increased data availability in a digitised society and robotic advances. Blockchain is another important technology for international law. Blockchain technologies are decentralised cryptographic systems (especially those used in the context of cryptocurrencies) that offer new possibilities for securely recording and verifying information.

The technological capacity of AI, blockchain and other new technologies can be used to effectively implement the provisions of international law through the creation of more advanced mechanisms of international control.

New technologies can primarily be used to monitor compliance with and prevent violations of international law. Advanced computer and robotic systems have capabilities to access, collect and process data that go beyond what humans can achieve. They can be used to document and analyse data in order to identify factual patterns that lead to possible violations of international law. Currently, there are already examples the potential of which can have a significant impact on the effectiveness of the implementation of international legal provisions. For example, the Wildlife Safety Assistant Project (PAWS - Protection Assistant for Wildlife Security) [9] has developed and implemented a machine learning algorithm that predicts where poaching attacks might occur. PAWS is a collaborative effort of computer 
scientists, researchers and conservationists from two non-governmental organisations, Panthera and Rimba.

PAWS builds on concepts and models of game theory, in particular security games, and provides an automated approach that generates efficient and randomised patrol schedules. Game safety research aims to overcome environmental protection challenges of the limited law enforcement resources. While optimising the security resource allocation, the previous work on Stackelberg Security Games (SSG) has resulted in many successfully deployed applications to improve the security of airports, ports and flights.

Another example is Sentry, an artificial intelligence technology developed by Hala Systems designed to predict air strikes and make it possible for civilians to find safe haven thereby enhancing the protection of civilians during armed conflicts. The Hala creators note that the technology is a commercial project that may be offered to public and private companies to monitor compliance with the international humanitarian law in conflict territories in the future. At present, the startup is being developed with investor money, as well as donations and grants from the governments of the United States, Great Britain and several other Western countries.

Secondly, advanced technologies can be used to investigate violations in the field of international law. In particular, the combination of detection and blockchain technologies can facilitate the detection of evidence used in court. Blockchain technologies offer new ways to record, authenticate and securely store and transmit information. In the context of international legal proceedings, blockchain can be used to verify and exchange evidence to ensure prosecution of international crimes. For example, in March 2018, the Global Legal Action Network (GLAN) announced the launch of a project exploring the use of blockchain to securely collect evidence in relation to the Yemen conflict [10].

Thirdly, new technologies can be used to solve global problems. It can be assumed that progressive AI capable of analysing information on a global scale can help in solving such problems as improving the international legal regulation of climate change, sustainable development, migration, countering terrorism and preventing armed conflicts.

An important legal aspect of digitalisation is privacy, non-discrimination and a broader respect for fundamental values and human rights. The important privacy implications of datadriven technologies are well known, and initiatives such as the EU General Data Protection Regulation (GDPR) seek to address them.

Accountability is another core issue in the use of new technologies. Technologies, that can make decisions and act autonomously, undermine the concept of responsibility, and the question of how to allocate accountability for harm caused by technologies that operate with limited human participation remains unresolved. The main legal thesis remains the possibility of maintaining "meaningful human control". At the same time, there is a discussion in the West about the legal personality of robots and their own responsibility, and a draft of the "ethical licence of a robot" is being discussed [11]. Those issues should be reflected in the international legal discourse.

\section{Conclusion}

The current AI regulatory framework is characterised by the proliferation of proprietary standards and guidelines developed by the industry (such as Google and Microsoft). Corporate self-regulation is a useful step but it remains voluntary and optional. In addition, private standards are not harmonised and are driven by different interests and values. In this context, the role of international law and institutions may be to coordinate the development of regulation, perhaps towards the development of internationally agreed principles that would also ensure that fundamental values are integrated into the AI design and development. 


\section{References}

1. K. Schwab, World Economic Forum (2016)

2. R. Rayfuse, Public International Law and the Regulation of Emerging Technologies, in R. Brownsword et al. (eds.), Oxford Handbook of Law, Regulation, and Technology (Oxford Press, Oxford, 2017)

3. S.B. Balkhaeva, Action of International Treaties in Time, Space and Circle of Persons: monograph, 185-186 (Infotropic Media, Moscow, 2019)

4. A. Aust, Handbook of International Law (Cambridge University Press, Cambridge, 2010)

5. Strategiya Generalnogo sekretarya $v$ otnoshenii novykh tekhnologii [Strategy of Secretary-General for New Technologies]. Accessed on: June 12, 2020. [Online]. Available: https://www.un.org/en/newtechnologies/images/pdf/SGs-Strategy-on-NewTechnologies-RU.pdf

6. E. Latifah, Brawijaya Law Journal, 5(2), 102-116 (2018)

7. IEAG-DR - 2014. A World That Counts: Mobilising the Data Revolution for Sustainable Development, in Report prepared at the request of the United Nations Secretary-General, by the Independent Expert Advisory Group on a Data Revolution for Sustainable Development, 1-2 (United Nations, New York, 2015)

8. Report of the High-level Committee on Programmes at its thirty-seventh session (United Nations Headquarters, New York, 8 and 9 April 2019). Accessed on: June 12, 2020. [Online]. Available: https://www.unsceb.org/CEBPublicFiles/CEB-2019-4HLCP37.pdf

9. F. Fang, B. Ford, R. Yang, M. Tambe, A.M. Lemieux, PAWS: Game Theory Based Protection Assistant for Wildlife Security, in M.L. Gore (ed.), Conservation Criminology (2017). https://doi.org/10.1002/9781119376866.ch10

10. B. Boutin, Blog of the Groningen Journal of International Law (2018)

11. R. Calo, A. M. Froomkin, I. Kerr (eds.), Robot Law (Edward Elgar Publishing, Northampton, 2016). Accessed on: June 12, 2020. [Online]. Available: http://repositorio.ucp.pt/bitstream/ 10400.14/22259/1/Robot\%20Law.pdf 